\title{
Effective Microgrid Synchronization in Islanded Mode: Controlled Input/output PI-Fuzzy-PI Algorithm
}

\author{
Solanke Tirupati U \\ Electrical \& Electronic Power Engineering \\ College of Engineering Ambajogai \\ Ambajogai. 431517 Maharashtra, India
}

\author{
Kulkarni Anant A. \\ Electrical \& Electronic Power Engineering \\ College of Engineering Ambajogai \\ Ambajogai. 431517 Maharashtra, India
}

\begin{abstract}
This paper Describe a feasible operation of micro grid. The micro grid is the combination of multiple distributed generators to solve global warming problems by reducing carbon dioxide emission in the electricity generation field had led to increasing interest in micro grids (MGs), particularly those containing the renewable sources such as solar and wind generation are widely used in actual practice due to easy availability of renewable source of energy. A Microgrid model, simulated on Matlab/Simulink software, is analyzed Due to wide use of these in isolated micro grid. This paper describe the new method of micro grid controlling Strategy introduced using Fuzzy-PI controller Algorithm using this technique the Islanded micro grid over come fluctuation problem the controller aims to optimize the better operation of micro grid central controller during the Islanded mode i.e. maximize the performance of micro grid. The developed operational algorithms are applied to the micro grid similarly the controller increases the performance of active power, variable frequency, phase angle, better synchronization the practical results are provided to validate the control scheme using PI- fuzzy-PI controller algorithm
\end{abstract}

Index Terms- BESS, DG, Micro grid, MCC, IED/STS, EPS

\section{INTRODUCTION}

The technological developments in the last few years are bringing up new forms and environmental issues changed the face of electricity generation and transmission systems. [1],[3] Reducing carbon emission in the electricity generation process, a recent technological development in micro generation domain, and electricity business restructuring are the main factors that led to the growing interest in using micro generations. In fact, connecting small generation units (micro sources) with power rating less than few tens of kilowatts to low-voltage networks potentially increases the reliability for end-users. This brings additional benefits to the global system operation and planning regarding investment reduction for future grid reinforcement and expansion. [13] The micro grid (MG) is intended to operate in the following two different modes.

1) Simple Mode: In this mode, the micro grid connected to main grid.

2) Islanded Mode/Isolated Mode: In this mode of operation of micro grid is disconnected from the to the main grid.
The grid is continually run in the Islanded Mode due to failure in the main grid or high disturbances created in the micro grid. Using the either renewable source of energy (e.g. wind and solar energy like co-generation mode). A Combined heat and power (CHP) system recovers waste heat and high efficiency, while improvements in reliability and power quality are the other benefits. By customizing the power quality of micro grid provide reliable and flexible power to consumer and provides benefits these can be classified into two major groups:

a. Economical/Environmental

b. Power quality

The number of micro grid studies conducted to control the mode of operation of micro grid and many major practical research projects underway all over the world. The basic control objective in a micro grid is to achieve accurate power sharing while maintaining close regulation of the micro grid voltage magnitude and frequency. Centralized control of a micro grid, based on a communication infrastructure is investigated in [16] the main sources of power in the MGs entrance into the power systems are based on the increasing reliability of the conventional power systems, as well as improvement of economical and environmental issues. [5] The MG islanding mode concept was laboratory tested and installed in the National Technical University of Athens (NTUA), which comprises a photovoltaic (PV) generator, battery energy storage, loads, and a controlled interconnection to an LV grid [17]. MatLab Simulink and its libraries (mainly the SimPower Systems toolbox) were employed in to develop a simulation platform suitable for identifying MG control requirements and evaluating MG dynamic behavior under several operating conditions.

The remainder of this paper is divided into four sections. Section I introduces several issues regarding the power control of DGs in a micro grid. In Section II, the economic dispatch problem and related constraints are formulated for a micro grid Section III presents the formulation of the constraint for the stable islanded operation in accordance with the power-sharing principle between the DGs. Section IV discusses the numerical simulation results which are utilized to investigate the effect of each constraint on the operational cost. Finally, Section V contains some concluding remarks.

\section{MICROGRID OPERATIONAL CONTROL}

This paper corresponds to an active scheme of synchronizing control system for the micro grid. Power system conventional 
restoration procedures are usually developed before any emergency situation occurs, which experience to deal with the problem. Furthermore, the size and specific characteristics of each of the actual power systems precludes the definition of a MicroGrid. The MicroGrid operational architecture was developed within the European Union R\&D MicroGrid project and is presented in Fig. 1. It comprises an LV network, MV network, HV network loads (some of them interruptible), both controllable and no controllable MS, storage devices, and a hierarchical-type management and control scheme supported by a communication infrastructure used to monitor and control MS and loads. The MG study architecture consists of a group of radial feeders, which could be part of a distribution system. There is a single point of connection to the utility called point of common coupling (PCC). Feeders 1 and 2 have sensitive loads which should be supplied during the events. The feeders also have the microsources consisting of a photovoltaic (PV), a wind turbine (WT), and fuel cell (FC), a microturbine (MT), a diesel generator (DG), and battery storage. The third feeder has only traditional loads the static switch (SD) is used to island feeders 1 and 2 from the utility when events happen. The fuel input is needed only for the DG, FC, and MT as the fuel for the WT and PV comes from nature. To serve the load demand, electrical power can be produced either directly by PV, WT, DG, MT, or FC. The diesel oil is a fuel input to a DG, whereas natural gas is a fuel input to fuel processor to produce hydrogen for the FC. The gas is also the input to the MT. The use of DG, or FC or MT with other fuel types can be modeled by changing the system parameters to reflect the change in the fuel consumption characteristics.

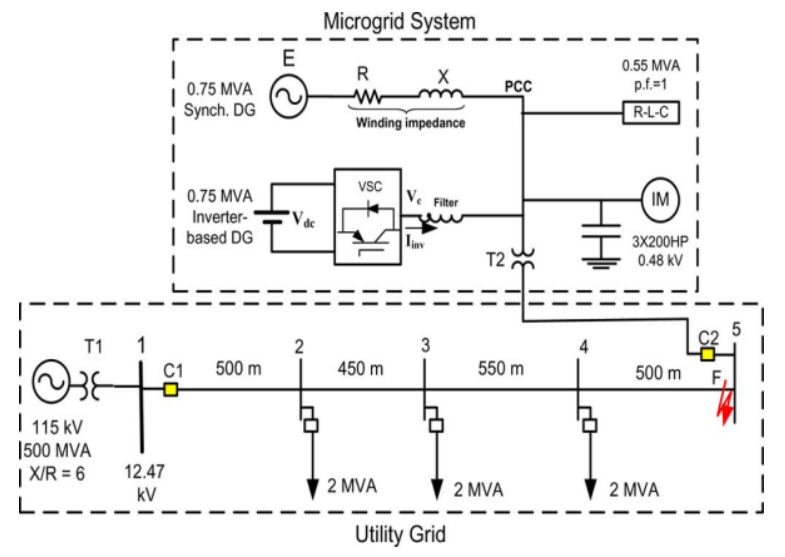

Fig. 1. Basic Structure of MicroGrid plant.

\section{A. Basic Scheme for Active Synchronizing}

Fig.1.Shows the MicroGrid central controller (MGCC) is the central control unit for the active synchronization scheme. Consist of at first the MicroGrid Central Controller decides the system's practical control according to the Electrical Power System performance. The intelligent electronic device IED send the operational signal to static transfer switch STS of each DG. Simultaneously each DG send analog signal towards IED and, then MCC calculates and distributes the control commands using synchronizing algorithm. Using this control algorithm controlling commands control the frequency, voltage, Phase angle using PI-Fuzzy-PI Algorithm
Fig.2. shows detail description of IED as well as STS the IED responsible for measuring the signals for the synchronization to ON/OFF. The IED senses signal the threephase parameters of each side and evaluate the phase difference, frequency these signals of both sides are to be compared and these compared results send towards the MicroGrid Central Controller (MGCC) via the network. While, the permissive commands from MGCC are enables the IED to switch ON/OFF when comparative results satisfy synchronizing criteria i.e. phase, Active power and Frequency. The reference phase transformation method is used to measure the phase difference and also we adopt the signal conditioner for unbalance voltage compensations. [12]- [13] The active power and frequency control we will briefly discuss some technical issues related to the active power and frequency control of DGs:

1) The power control mode: The power output of a DG can be

Controlled by one of two different modes: Unit output power and feeder flow control (FFC) [18].

2) Power-Sharing During Microgrid Islanding: When a microgrid is disconnected from the main grid.In many studies, power versus frequency droop control has been adopted in order to ensure that the power demand is dynamically balanced by the DGs [5]-[8]. Conventionally, the droop constant of a DG is considered to be a fixed parameter, determined so that the load demand is shared among DGs in proportion to their rated capacities. In [14] and [15], a new power-sharing principle is proposed in which the droop constants are periodically modified according to the operating points of the DG units. With this method, the DGs share power according to their operational reserves, rather than their capacities.

\section{B. Active Synchronization}

The MicroGrid control operation is fully controlled using a hierarchical approach for decentralized control. In actual practice the various controlling methods are considered like primary, secondary and tertiary control level. In this paper the secondary level is to be considered in this the only voltage and frequency recovered due to The every controllable DG is able to adjust the both voltage and frequency set points, so that MCC can generate the offset commands and delivers them to each generating unit via the same network.[8] The frequency difference is due to the disagreement in the rotational speed of DG to reduce these frequency difference PI controller is used but instead of using PI controller the effective scheme for frequency control is the fuzzy control scheme is also used for fast response. For example solar fuel cell has fastest response for long time to change the output, is responsible for the higher frequency band but in actual practice the solar fuel cell MicroGrid plant.

The diesel generator takes a long time to get the desired frequency its responsible for the lowest frequency band using the low pass filter. 


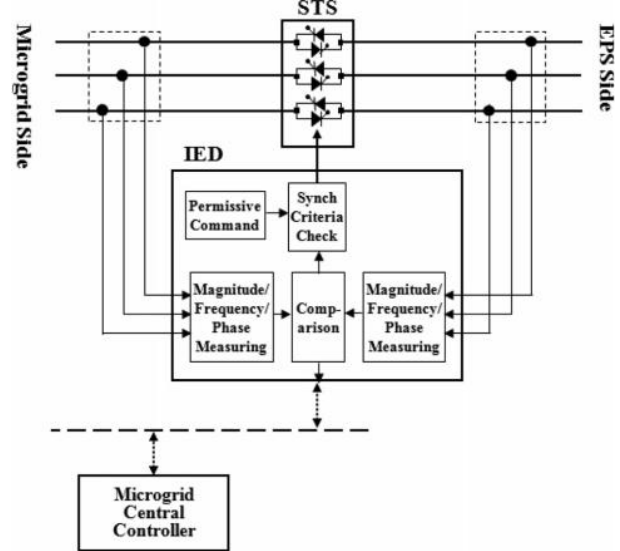

Fig.2. Scheme of IED/STS

Although the all frequencies are matched perfectly the switch cannot be turned ON due to phase difference. The installation of a separate DG that is wholly responsible for the phasedifference control would give us the best solution. However the limited number of DG can responsible for the high frequency can serve the as perfectly phase-difference controller. The Fig. 3. Shown results the unpredictable with the frequency difference control and also for the phase difference. To nullify this frequency-difference the PI controller used and for the phase-difference control fuzzy controller can be used.The voltage difference signal 2 is signal that indicates the voltage difference between the MicroGrid and Electrical power system. As the frequency difference control is passed through PI controller and voltage difference control signal is passed through the fuzzy controller. The angle difference signal 3 is passed through the PI controller and the desired weight factors can be estimated in the MCC which are adjusted as per the individual characteristics of the each DG.

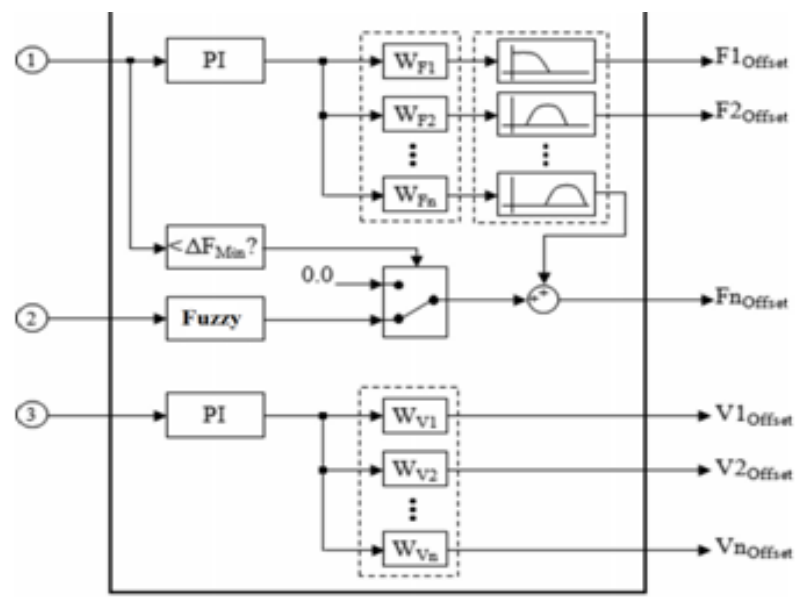

Fig.3.New PI-fuzzy-PI Algorithm for the synchronization

\section{DESIGN OF CONTROLLER AND SIMULATION}

In the following sections, the conventional proportional integral (PI) controller, Fuzzy controller is briefly described, while the three proposed controllers are described in detail.

\section{A. Conventional PI-Fuzzy-PI controller}

The conventional PI controller scheme is shown in Fig. 4 it is used to maintain the output power of the wind generator like BESS and also for DG at its rated level. Therefore, the limitations of this controller are described in detail as the advantages of the conventional PI controller are its simple and reliable features. The disadvantage of the PI controller is that it works only when the wind speed exceeds the nominal value. Therefore, it cannot help in the smoothing of the output power

The new implemented adaptive control scheme is used to improve the performance of MicroGrid in Islanded mode of operation. Using the fuzzy control algorithm the new control scheme is develop by simple controlling the phase difference

The efficient synchronization can be occurred above the unit network modeled delay of $520 \mathrm{~ms}$. The effect of synchronizing performance can be seen at the different network delay modeled as a zero-order hold with time delay element. [14]For the exact comparison with the same conditions, the digital filters of the MCC are recalculated at each case.

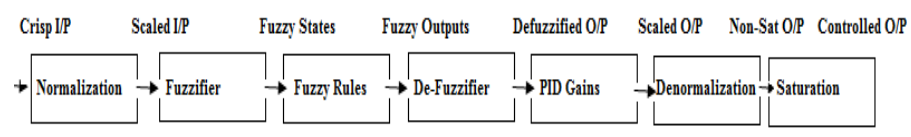

Fig. 4. Fuzzy design procedure

The cascade structure of a conventional PID controller, a one-input fuzzy PI controller is proposed an error signal is defined by with being a reference input, and a plant response at time instant. The controller output (or, control input to a plant) [4] the triangular membership functions defined for single the Input three fuzzy rule base system is used the fuzzy member ship functions are mamdani with the three control rules described in the Fig.5.

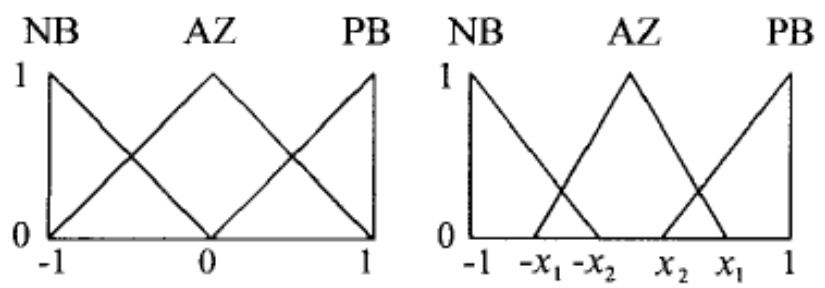

Fig.5. Fuzzy membership functions using three rules 


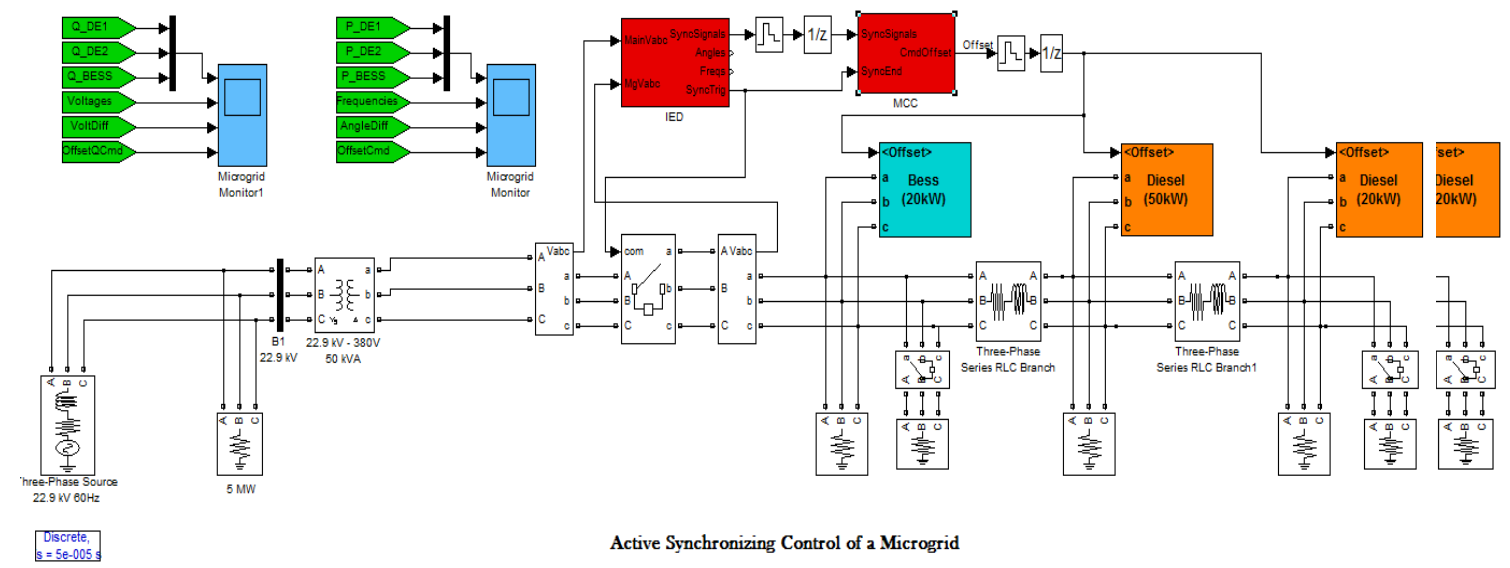

Fig.7. Synchronization of Microgrid

\section{B. Dynamic Modeling and simulation results}

The feasibility of active and reactive power sharing starts with the active and reactive power flows between the two ac power sources through the impedance $\mathrm{Z}=\mathrm{R}+\mathrm{jX}$.[6] The active

The power is the real power can be defined as actual available voltage into actual current and the active power is always Positive meanwhile the reactive power is average of actual power and active power these two different powers present in EPS due to the resistive / inductive load. The active power $\mathrm{P}$ and reactive power Q shown in Fig.6

\section{Dynamic Modeling and simulation results}

The feasibility of active and reactive power sharing starts with the active and reactive power flows between the two ac power sources through the impedance $Z=R+j X$.[6] The active power is the real power can be defined as actual available voltage into actual current and the active power is always

Positive meanwhile the reactive power is average of actual power and active power these two different powers present in EPS due to the resistive / inductive load. The active power $\mathrm{P}$ and reactive power Q shown in Fig.6
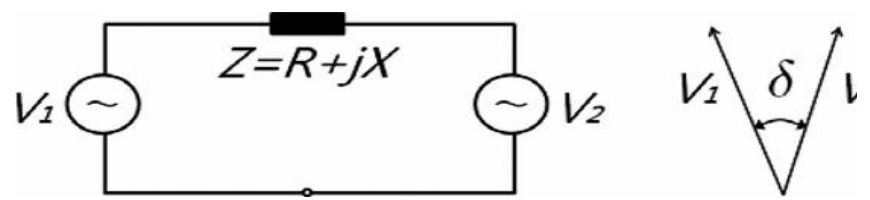

Fig.6. Two DGs connected by line impedance

$$
\begin{aligned}
& P=\frac{V 1}{R^{2}+X^{2}}[R(V 1-V 2 \cos A)+X V 2 \sin A] \\
& Q=\frac{V 1}{R^{2}+X^{2}}[(-R V 2 \sin A)+X(V 1-V 2 \cos A)]
\end{aligned}
$$

If the transmission line is mainly inductive loads, where the resistance can be neglected, and phase angle between two voltages is given as

$$
\begin{aligned}
& P=\frac{V 1 V 2}{X^{2}}[\sin A] \\
& Q=\frac{V 1}{X}[V 1-V 2]
\end{aligned}
$$

These equations can implies the exact active and reactive powers are proportional to the voltage difference and phase angle difference to verify the effectiveness of the active scheme of synchronization control of an Isolated MicroGrid.[1] we built the new simulation using MATLAB/Simulink software using simpower system toolbox and Control system toolbox. Which contains the circuit breakers, transformers, RLC loads, transmission line the designing allows dynamic model to fast and simply to simulate power systems.

Fig.7. shows the simulation setup of active synchronization the electrical power system simulated for the MicroGrid. The detailed dynamic behavior for MCC, BESS, DG1, and DG2 are also described. Based on a survey report four devices are widely used for manual/auto synchronization presently. These devices are Sync-check relays, voltage relays, synchronizing relays and the automatic synchronizer.[11][12] The traditional method for measuring the synchronizing criteria is to use the zero crossing signals of two voltages. Zero crossing method is widely used because it has a simple structure and it provides high accuracy. However it has major disadvantages, particularly on long measurement period and is weak against harmonics and noises

\section{Synchronization Model}

As described in the previous section, a synchronizer model was developed Fig.8. The synchronizer takes two three-phase voltage signals as the input. Then, each signal is sent to the signal conditioner. The signal conditioner blocks Fig.9. makes the three-phase balanced signal that will eliminate the 
side effects of an imbalance.[1] The block uses a three-phase sequence analyzer to make a positive-sequence voltage and Matlab function named SigConditioner is for producing virtual three-phase balanced signals.[11] We had used a discrete virtual PLL block to produce $60-\mathrm{Hz}$ reference sine and cosine signals. Signals after the signal conditioner are used in the frame transformation block (Angle Detect) to check each magnitude and phase angle. Matlab function Synchro produces the phase-angle difference (Sync Angle) and generates the breaker trigger signal when the synchronizing criteria are met For the control of the engine speed and the generator voltage, a Sync- Ctrl block exists. For the control of generator output voltage, a PI regulator was used. And for the control of engine

speed and synchronization, a simple rule-based controller was used.

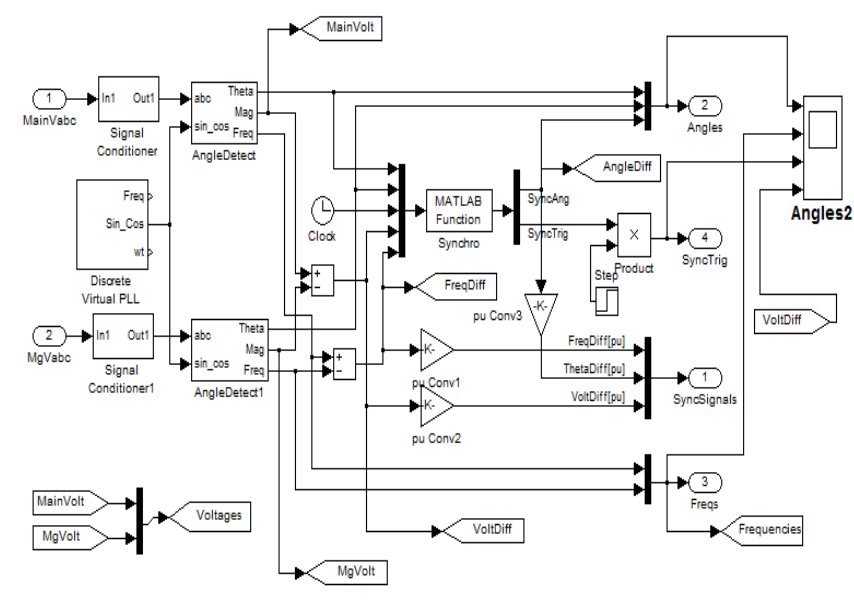

Fig.8. Synchronizer model control

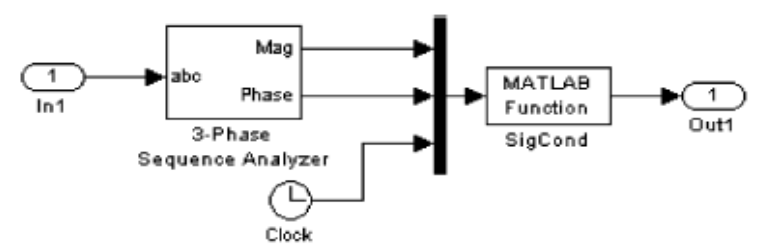

Fig.9. Signal Conditioner

\section{E. Simulation result Discussion.}

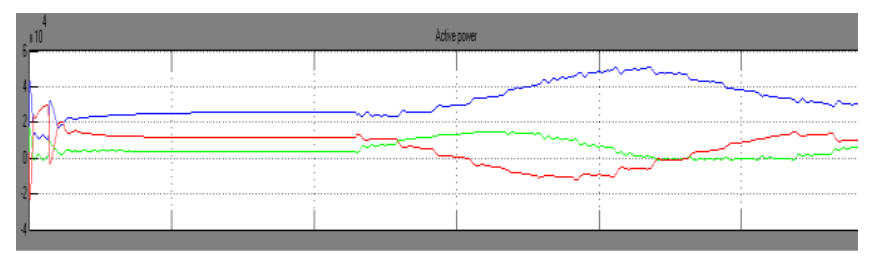

(a)Active Power

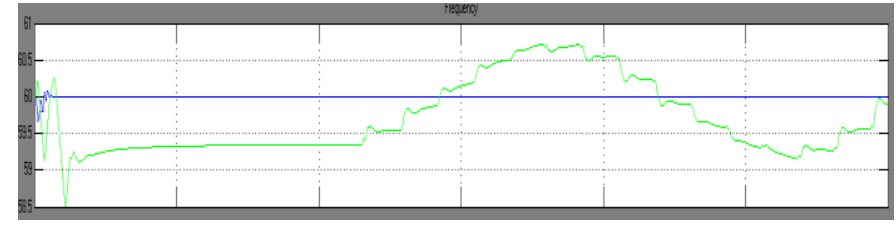

(b) Frequency

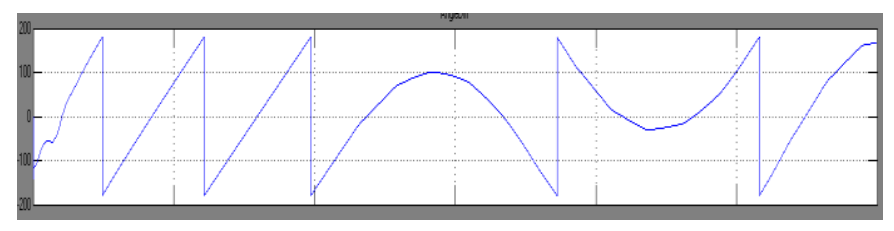

(c) Angle Difference

Fig.10. Simulation results using PI-fuzzy-PI Algorithm at $520 \mathrm{~ms}$ time delay

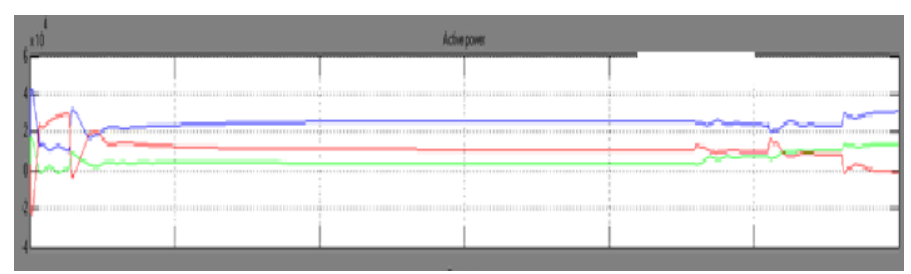

(a) Active Power

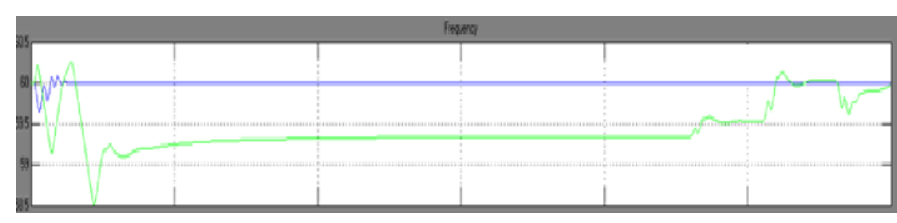

(b) Frequency

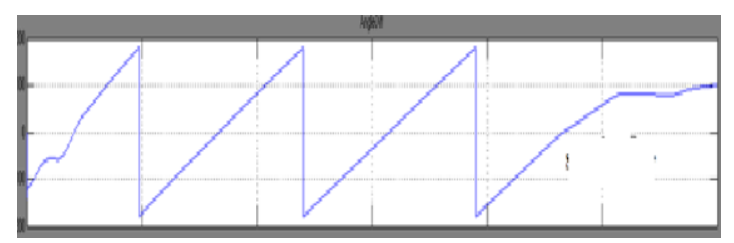

(c) Angle Difference

Fig.11. Simulation results using PI Algorithm at 500ms time delay

Using the dynamic model of the MicroGrid with the active Synchronizing control scheme in Fig.7. The Matlab simulation is performed. Due to the limitation of the simulation time, the rate limiters of the DG's offset command input are intentionally discarded The results are shown in Fig. 10 for the case of 520ms network delay. The three graphs in the first row show the variations of the active powers of DGs (red: DE1, green: DE2, blue: BESS) for each case, respectively. The second row shows the graphs of the frequency variations (blue: EPS, green: MicroGrid). The 
graphs in the third row show the trajectories of the angle difference for the 520ms network delay. Finally the graphs at the bottom are the offset commands (red: DE1, green: DE2, blue: BESS).

It is shown in the figure that the active synchronization is initiated at $520 \mathrm{~ms}$. Then, by the control Algorithm of the MCC, the offset command is distributed to the DGs through the frequency filters. It can be seen that the active power is distributed among the controllable DGs along the synchronization process. To see the network delay effect to the synchronizing control performance, the simulation case with $500 \mathrm{~ms}$ is selected. The network delay is modeled as a zero-order hold with a time-delay element. For the exact comparison with the same conditions, the digital filters of the MCC are recalculated at each case. For 520ms delay, using PI-fuzzy-PI controller i.e. input as well as output also controlled using this algorithm the simulation shows that a smooth synchronization is achieved. And the simulation result for 520-ms delay shows marginally acceptable in synchronization. However, for the case of 520-ms delay, the synchronization cannot be achieved using the PI controller Algorithm and the failure in MicroGrid operation is observed. Using this algorithm the time required for synchronization is reduced up to 2.5-2.7 second so it has effectively controlled soft synchronization. The table I show the comparative result obtained

TABLE I

\begin{tabular}{|c|c|c|c|c|}
\hline & \multicolumn{4}{|c|}{ Synchronizing results at above $500 \mathrm{~ms}$ network delay } \\
\hline $\begin{array}{l}\mathrm{Sr} \\
\text { no. }\end{array}$ & $\begin{array}{l}\text { Synchronizing } \\
\text { criteria }\end{array}$ & $\begin{array}{l}\text { PI } \\
\text { controller }\end{array}$ & $\begin{array}{l}\text { Fuzzy } \\
\text { Controller }\end{array}$ & $\begin{array}{l}\text { PI- } \\
\text { Fuzzy-PI } \\
\text { Controlle } \\
r\end{array}$ \\
\hline 1 & $\begin{array}{l}\text { Frequency +/- } \\
0.1 \mathrm{~Hz}\end{array}$ & $\begin{array}{l}60.5 \text { to } 61.5 \\
\mathrm{~Hz}\end{array}$ & $\begin{array}{lll}60 & \text { to } & 60.5 \\
\mathrm{~Hz} & & \end{array}$ & $60.5 \mathrm{~Hz}$ \\
\hline 2 & $\begin{array}{l}\text { Angle } \\
\text { difference } \\
<+/-2 \text { deg. }\end{array}$ & $+75 \mathrm{deg}$ & $+80 \mathrm{deg}$ & $\begin{array}{l}>=80 \\
\text { deg. }\end{array}$ \\
\hline 3 & $\begin{array}{l}\text { Synchronizati } \\
\text { on time in } \\
\text { second }\end{array}$ & $\begin{array}{l}\text { After } \quad 4.5 \\
\text { sec. }\end{array}$ & $\begin{array}{l}\text { After } \quad 4.0 \\
\text { sec. }\end{array}$ & $\begin{array}{l}\text { After } 2.7 \\
\text { Sec. }\end{array}$ \\
\hline 4 & Active power & $\begin{array}{l}\text { Uncontrolle } \\
d\end{array}$ & Controlled & $\begin{array}{l}\text { Effective } \\
\text { ly } \\
\text { Controlle } \\
d\end{array}$ \\
\hline 5 & $\begin{array}{l}\text { Synchronizati } \\
\text { on }\end{array}$ & Unbalanced & Balanced & Effective \\
\hline
\end{tabular}

\section{IV.CONCLUSION}

This paper has introduced the new implemented synchronizing method. The proposed method after the network delay of above $500 \mathrm{~ms}$ i.e. $520 \mathrm{~ms}$ provides a precise measurement, and consequently enables the smooth synchronization at 2.5-2.7 sec. and soft connection between the synchronous generator and the electric power system is
observed.The reference frame transformation-based synchronizing criteria measurement, together with the signal conditioner and the phase-angle difference estimation, has enabled the perfect match between the synchronous generator and the EPS. This paper has presented the analytic comparative study. Between the PI Algorithm, fuzzy algorithm the validation of the proposed method was performed. And the comparative results with the PI-Fuzzy-PI algorithm showed the definite difference using this algorithm. The results can be also improved using new ideas for the various Single input Single output controller algorithms using the PSCAD. The paper deals the concluded results so the aggregation of DG sources to form a microgrid under co-ordination control

\section{APPENDIX}

The parameters in the experimental study are as follows.

Diesel generator 1

- $\quad$ Rating: $50 \mathrm{~kW}, 380 / 220 \mathrm{~V}, 3 \Phi 4$ wire, $1800 \mathrm{r} / \mathrm{min}$, $60 \mathrm{~Hz}$

- $\quad F$-controller: gain $(K p r=004)$ integral $(T n=2.0)$.

- $\quad V$-controller: gain $(K p r=005)$ integral $(T n=2.0)$.

$\operatorname{Ramp}(002 \% / \mathrm{s})$.

Diesel generator 2

- $\quad$ Rating: $20 \mathrm{~kW}, 380 / 220 \mathrm{~V}, 3 \Phi 4$ wire, $1800 \mathrm{r} / \mathrm{min}$, $60 \mathrm{~Hz}$

- $\quad$ Exciter: brushless self-excited

- $\quad$ MOP: control range (+/-10\%), speed (90 s/span).

- $\quad$ AVR gains: $K p=1.2, K i=3.4$

- Power controller: $K p=0.4, K d=14$, Droop = $1.0 \%$.

Battery energy storage system $3 \Phi 4$ wire.

Rating: $20 \mathrm{~kW}, V \mathrm{dc}$ link $=700 \mathrm{~V}$, Battery $=450 \mathrm{~V}$,

- $\quad$ Battery: lead-acid, 36 serial 2 parallel, 500 Ah 200

$\mathrm{kWh}$.

- $\quad F$ controller: $K p=50, K i=30$.

- Power controller: $K p=1.5, K i=150$, Droop $=$ $2.0 \%$.

Photovoltaic system

- $\quad$ Rating: $10 \mathrm{~kW}, \mathrm{PV}$ module $=48 \mathrm{Wp} 48$ ea.

- $\quad$ Dual-axis-type solar tracker, MPPT.

Wind turbine

- $\quad$ Rating: $10 \mathrm{~kW}, 3$ blade, auto furling.

- Wind speed: cut-in $3.3 \mathrm{~m} / \mathrm{s}$, nominal $13 \mathrm{~m} / \mathrm{s}$, max $40 \mathrm{~m} / \mathrm{s}$.

- Generator type: PMSG.

Active synchronizing controller

- $\quad$ Digital filter: sampling time $62 \mathrm{~ms}$. 
- $\quad$ Low-pass filter: $F$ cutoff $=0.1 \mathrm{~Hz}$.

- $\quad$ Band-pass filter 1: $F$ center $=0.3162 \mathrm{~Hz}$

- $\quad$ Bandwidth $=9.99 \mathrm{~Hz}$.

- $\quad$ Band-pass filter 2: $F$ center $=3.1623 \mathrm{~Hz}$,

- $\quad F$ bandwidth $=99.9 \mathrm{~Hz}$.

- $\quad$ Weight factors: $w 1=0.2, w 2=1.0, w 3=1.0$.

- $\quad$ Frequency PI controller gains: $K p=2.0, K i=0.9$.

- Phase difference PI controller gains: $K p=5.0, K i=0.9$

- Voltage difference PI controller gains: $K p=3.0, K i=0.9$.

- $\Delta F \mathrm{Min}: 0.055 \mathrm{~Hz}$

Synchronizing criteria.

- $\quad$ Estimated phase-difference angle $<+/-2^{0}$

- $\quad$ Slip frequency $<+/-0.1 \mathrm{~Hz}$

- Voltage difference $<+/-3 \%$.

\section{REFERENCES}

[1] Changhee Cho, Jin-Hong Jeon, Jong-Il Kim "Active synchronization of MicroGrid,"vol. 26, no 12 December 2011.

[2] R. M. Kamel, A. Chaouachi, and K. Nagasaka, "Carbon emissions reduction and power losses saving besides voltage profiles improvement using micro grids," Low Carbon Economy J., vol. 1, no. 1, pp. 1-7, Sep. 2010.

[3] R. M. Kamel, A. Chaouachi, and K. Nagasaka, "Design and testing of three earthing systems for micro-grid protection during the islanding mode," Smart Grid Renewable Energ. J., vol. 1, no. 3, pp. 132-142, Dec. 2010.

[4] V. S. C. Raviraj and P. C. Sen, "Comparative study of proportional integral, sliding mode, and fuzzy logic controllers for power converters," IEEE Trans. Ind. Appl., Vol. 33, No. 2, pp. 518-524, Mar./Apr. 1997

[5] R. H. Lasseter, "Micro Grids," in Proc. IEEE Power Eng. Soc. Winter Meeting, Jan. 2002, vol. 1, 305-308.

[6] R. H. Lasseter, "Extended CERTS MicroGrid," in Proc. IEEE Power Energy Soc. General Meeting, Jul. 2008, pp. 1-5.
[7] I. S. Jacobs and C. P. Bean, "Fine particles, thin films and exchange anisotropy," in Magnetism, vol. III, G. T. Rado and H. Suhl, Eds. New York: Academic, 1963, pp. $271-350$.

[8] C. Xiarnay, H. Asano, S. Papathanassiou, and G. Strbac, "Policymaking for micro grids," IEEE Power Energy Mag., vol. 6, no. 3, pp. 66-77, May/Jun. 2008.

[9] K. Yeager, "Striving for power perfection," IEEE Power Energy Mag., vol. 6, no. 6, pp. 28-35, Nov./Dec. 2008.

[10] M. M. Begovic, P. M. Djuric, S. Dunlap, and A. G. Phadke, "Frequency tracking in power networks in the presence of harmonics," IEEE Trans. Power Del., vol. 8, no. 2, pp. 480-486, Apr. 1993.

[11] J.-Z. Yang and C.-W. Liu, "A precise calculation of power system frequency and phasor," IEEE Trans. Power Del., vol. 15, no. 2, pp. 494-499, Apr. 2000.

[12] T. Sezi, "A new method for measuring power system frequency," in Proc. IEEE Transmits. Distrib. Conf., Apr. 1999, vol. 1, pp. 400-405.

[13]C. Cho, S.-K. Kim, J.-H. Jeon, and S. Kim, "New ideas for a soft synchronizer applied to CHP cogeneration," IEEE Trans. Power Del., vol. 26,no. 1, pp. 11-21, Jan. 2011.

[14] F. Katiraei, R. Iravani, N. Hatziargyriou, and A. Dimeas, "Microgrids management-controls and operation aspects of microgrids," IEEE Power Energy Mag., vol. 6, no. 3, pp. 54-65, May/Jun. 2008.

[15] Baogang Hu, Senior, George K. I. Mann, Raymond G. Gosine, "A new methodology for analytical and optimization of fuzzy PID controller" vol. 26. No 19 October 1999. K. Elissa

[16] J. A. P. Lopes, C. L. Moreira, and A. G. Madureira, "Defining Control strategies for microgrids islanded operation," IEEE Trans. Power Syst., vol. 21, no. 2, pp. 916-924, May 2006.

[17] D. Georgakis, S. Papathanassiou, N. Hatziargyriou, A Engler, And C. Hardt, "Operation of a prototype micro grid system based On micro-sources equipped with fastacting power electronic Interfaces," in Proc. IEEE 35th PESC, vol. 4, Aachen, Germany, 2004, pp. 2521-2526.

[18] R. H. Lasseter, "Control and design of microgrid components," PSERC Final Project Reports [Online]. Available: http://www.pserc. 